Theories \& Applications, the International Edition

Printed Version: (ISSN 2090-5262)

Online Version: (ISSN 2090-5270)

November 2013, Volume 3, No. 3 Pages (108 - 114)

\title{
Athletics Players' Sport Injuries of Different Competitions and Their Reasons
}

\author{
Mahmoud Youssef Mohamed*
}

\section{Research Introduction \& Problem}

A thletics are considered the essence of all sport games, and there are millions of athletes who practice different champions of Athletics not as competitions but as healthy and recreational means but injuries may deprive them from practicing their hobbies. Athletics' injuries are of the kinds, places and reasons that negatively affect the efficiency of different body systems, and the level of players' physical and mental shape. (1694:14).

Injury is one of the problems that player faces during training period or during performing the practice according to the performance nature of the practiced activity and what it requires of technical potentials necessary to perform this activity. (1:8)

The scientific progress in medical science and using advanced methods in treatment and rehabilitation led to the interest of rehabilitation and prevention researches, that aims to athlete's return to playgrounds in the shortest time possible, and that he regains his sport shape as it was before injury. (336:8), (2:7)

Injury is considered one of the obstacles that hinders athletic activity and affects athletic performance in general; consequently its negative influence appears on the athlete and competitions' results due to athlete's absence for long periods, and may result in physiological changes in internal body systems and in turn reduces athlete's efficiency than before the injury. (11:3), (1:1), (249:2).

John \& Williams and AbdoNassif clarify that, despite the absence of direct contact between athletes in some sports, their injuries are due to

* Faculty of Sport Sciences \& Physical Activity, King Saud University, Saudi Arabia. the contact between athlete's body and the ground or body self inertia resistance as in track and field competitions (13:53), (16:5)

Athletic injuries happen due to intrinsic factors attached to the health and physical status of the athlete or as a result of the extrinsic factors that surround activity practice (such as tools, equipments, rules and principles of competitions and training method, climate and sport building status). Injuries could be due to complicated and interrelated intrinsic and extrinsic factors. (16: 46), (111: 18).

Proceeding from theoretical studies that confirmed the fact that Athletics injuries are of the most important and common injuries in the European sport society concerning the number and kind of injury. Daren (1981) concluded that Athletics injuries had occupied the fourth place among a group of studied sport activity. (69: 11).

Mechlen (1992) pointed out that Athletics injuries had occupied the fifth place in classifying many sport activity injuries under study. As he distinguished injuries according to functional nature of movement performance and concluded that muscle cringe of Athletics players represent the highest rate among all injuries as it reached (71.5\%). (12:14)

Hence we find that defining kind, degree and reason of sport injuries that occur to different competitions athletes of first class and youth Athletics. The difference of sport injuries in foreign researches and studies does not suit our societies due to its different research societies and because injuries differ completely from one society to another, from one level to another and from one age group to another.

The researcher through his work as a participating professor in playground injuries who knows the lack of scientific studies and researches in Athletics in the Saudi Kingdom, 
this urged him to choose this problem to be the light that the trainer and athlete's injuries specialist can use to make the necessary arrangements in order to prevent and decrease playing injuries that hinder the athletes for long periods while the club team could be in desperate need for their efforts to obtain a place or a medal.

Keyword: Athletics - injuries

\section{Research Aims:}

This research aims to recognize:

1. The differences among the kinds of the most common injuries in different competitions in Athletics players.

2. The differences among places of the most common injuries in different competitions in Athletics players.

3. The reasons behind sport injuries of Athletics players.

\section{Questions:}

1. What are the differences among kinds of the most common injuries in different competitions in Athletics players?

2. What are the differences among places of the most common injuries in different competitions in Athletics players?

3. What are the reasons behind sport injuries of Athletics players?

\section{Research procedures:}

\section{First: research sample:}

The research sample is selected of (220) student of Athletics players from faculties of King Saud University, their ages from (18-25) years, (100) running player, (66) jumping player and (54) throwing players.

\section{Second: research method:}

The researcher used the descriptive method as it suits the nature of the study.

\section{Third: data base means:}

\section{Data base form:}

1. Personal interview.
2. Athlete's questionnaire has been shown to experts enclose no. (1) in injuries field, they are (6) university professors, and physiotherapyspecialists.

\section{Expert's selection conditions:}

- Academics that have a Ph D. degree and work in the specialized field for 8 years.

- Physiotherapy specialists of at least 10 years experience.

Table (1)

The mean, standard deviation and Skewness of Athlete's height, age and weight variables

\begin{tabular}{|c|c|c|c|}
\hline \multirow{2}{*}{ Variables } & \multicolumn{3}{|c|}{ Athletes } \\
\cline { 2 - 4 } & $\mathrm{M}$ & Standard Deviation & Skewness \\
\hline Height & 174.4 & 3.83 & -1.59 \\
\hline Age & 20.9 & 0.83 & -1.51 \\
\hline Weight & 73.14 & 4.31 & 2.24 \\
\hline
\end{tabular}

Table (1) shows that skewness of athlete's height, age and weight variables are limited between $( \pm 3)$, which refers to the coherence of society sample.

\section{Data base}

The researcher used sport injuries form which was used before in (Mahmoud Youseef) Study 2005. The researcher changed some phrases to suit the research and displayed it on (8) experts; (6 academics of university professors that work in the same field (injuries), and (2) playground injuries specialists, enclose no. (1). They approved its validity to be applied which confirms form honesty. Stability correlation of kinds, and places of sport injuries was also calculated and reached (0.93), (1), and the form of sport injuries reasons which reached (0.98). Enclose no. (2).

The form stability was done by applying the form on a sample of (10) athletes out of the original sample then the form was re-applied once more after (15) days, until it became in its final shape.

\section{Statistical treatment}

1. Arithmetic mean.

2. Standard deviation.

3. Skewness.

4. Percentage rates.

5. Differences significance. (C2)

Notice: Considering the difference of sample number in each competition, it was calculated: percentage rate $=$ the number of injury repetition 
on the total injuries repetitions of each competition.

First: Result Display of the First Questionnaire

Table (2)

Percentage of Rate Differences Research Sample of Sport Injuries kinds $(N=220)$

\begin{tabular}{|c|c|c|c|c|c|c|c|c|c|c|}
\hline \multirow{2}{*}{$\begin{array}{c}\text { No } \\
\text {. }\end{array}$} & \multirow[t]{2}{*}{ Injury kind } & \multicolumn{2}{|c|}{$\begin{array}{l}\text { Running } \\
\text { players }\end{array}$} & \multicolumn{2}{|c|}{$\begin{array}{l}\text { Jumping } \\
\text { players }\end{array}$} & \multicolumn{2}{|c|}{$\begin{array}{c}\text { Throwing } \\
\text { players }\end{array}$} & \multirow[t]{2}{*}{ total } & \multirow[t]{2}{*}{$\%$} & \multirow{2}{*}{$\mathrm{C} 2$} \\
\hline & & $\mathrm{C}$ & $\%$ & $\mathrm{C}$ & $\%$ & $\mathrm{C}$ & $\%$ & & & \\
\hline 1 & Bruising & 78 & 23.78 & 59 & 28.92 & 20 & 16.53 & 157 & 24.04 & $* 33.41$ \\
\hline 2 & Rupture & 117 & 45.67 & 67 & 32.84 & 48 & 39.67 & $\begin{array}{c}232.0 \\
0\end{array}$ & 35.53 & $* 32.86$ \\
\hline 3 & Breaking & 8 & 2.44 & 12 & 5.88 & 2 & 1.65 & 22 & 3.37 & $* 6.91$ \\
\hline 4 & Torsion & 27 & 8.23 & 39 & 19.12 & 18 & 14.88 & 84 & 12.86 & $* 7.93$ \\
\hline 5 & Dislocation & 1 & 00.31 & 5 & 2.46 & 2 & 1.65 & 8 & 1.23 & 3.25 \\
\hline 6 & Cringe & 97 & 29.57 & 22 & 10.78 & 31 & 25.62 & 150 & 22.97 & 67.08 \\
\hline & Total & 328 & 100 & 204 & 100 & 121 & 100 & 653 & 100 & \\
\hline
\end{tabular}

* Statistically significant.

Table (2) shows that there are statistically shown differences in bruising, breaking, torsion and cringe while there are no statistically shown differences in dislocation.

\section{Result Discussion of First Questionnaire}

In table (2) there are statistically shown differences between athletes in bruising in favor of jump players as it reached (28.92\%). There are statistically shown differences in rupture in favor of throwing players at the rate (39.67), there are statistically shown differences in breaking in favor of jumping players rated $(5.88 \%)$, there are statistically shown differences in torsion in favor of jump rated $(19.12 \%)$.

The researcher sees that bruising in jumping players resulted from falling on mattresses in high jumping, leaping vault and falling on the sand. Rupture in long jumping athletes' may be due to running at the maximum speed to throw the spear or the disk with the maximum power using arm, elbow, and shoulder joints or during turning and pushing the disk at the maximum speed that could be much tougher than muscle endurance ability which result in muscle, string or tie rupture.

These results agreed with what NazmiDarwish and others (1985) concluded that sport injuries of throwing players (28.3\%), and rupture, torsion, bruising, inflammation of knee and wounds. Long jump and the triple jump competitions are the most ones that are exposed to athletes' injuries followed by running and hurdles. (395: 10)

Ekstrand\&Gillicquist (1983) point out that muscle ruptures and cringes spread due to sudden physical effort and extra training load that result in such injuries. (267:12)

By displaying and discussing the previous tables, the first question was answered which is: what are the differences between kinds of the most common injuries in different competitions of athletics' players? 
Table (3)

The differences and the percentage rate of sport injuries places studied in the research $(N=220)$

\begin{tabular}{|c|c|c|c|c|c|c|c|c|c|c|}
\hline \multirow{2}{*}{ No. } & \multirow{2}{*}{$\begin{array}{l}\text { Injury } \\
\text { places }\end{array}$} & \multicolumn{2}{|c|}{ Running players } & \multicolumn{2}{c|}{ Jump players } & \multicolumn{2}{c|}{ Throw players } & \multirow{2}{*}{ total } & \multirow{2}{*}{$\%$} & \multirow{2}{*}{$\mathrm{C} 2$} \\
\hline & c & $\%$ & $\mathrm{c}$ & $\%$ & $\mathrm{c}$ & $\%$ & & & \\
\hline 1 & shoulder & 50 & 15.24 & 32 & 15.69 & 39 & 32.23 & 121 & 18.53 & 4.08 \\
\hline 2 & elbow & 12 & 3.66 & 21 & 10.29 & 10 & 8.26 & 43 & 6.58 & 4.79 \\
\hline 3 & hand & 37 & 11.28 & 42 & 20.59 & 29 & 23.97 & 108 & 16.54 & 2.39 \\
\hline 4 & chest & 7 & 2.13 & 5 & 2.45 & 5 & 4.13 & 17 & 2.60 & 0.53 \\
\hline 5 & thigh & 38 & 11.59 & 16 & 7.84 & 6 & 4.96 & 60 & 9.19 & $* 26.8$ \\
\hline 6 & leg & 31 & 9.45 & 8 & 3.92 & 7 & 5.79 & 46 & 7.04 & $\begin{array}{c}* 24.0 \\
4\end{array}$ \\
\hline 7 & knee & 53 & 16.16 & 31 & 15.20 & 7 & 5.79 & 91 & 13.94 & $\begin{array}{c}* 34.9 \\
0\end{array}$ \\
\hline 8 & foot & 80 & 24.39 & 36 & 17.66 & 10 & 8.26 & 126 & 19.30 & $* 59.6$ \\
2
\end{tabular}

* Statistical significance

Table (3) shows that there are statistically shown differences in thigh, leg, knee and foot while there are no statistically shown differences in shoulder, elbow, hand, chest, face and back.

\section{Result Discussion of Second Question}

Table (3) shows that there are statistically significant differences in thigh injuries among athletics players in favor of running players as it reached $(11.59 \%)$. There are statistically significant differences in leg injuries in favor of running players reached $(9.45 \%)$, there are statistically significant differences in knee injuries in favor of running players reached (16.16), and there are statistically significant differences in foot injuries in favor of running players reached $(24.39 \%)$.

The researcher sees that foot and knee injuries occupied the highest injury rate that may happen due to the contact and clash between players during running in the track turn or running with the maximum speed that exceeds player's ability at the end line, while thigh and leg injury is due to the level of physical fitness and body weight on leg and thigh when exerting intensive physical effort especially in marathon champions.

This result aggress with both Mechelen (1992) and Ojendijk,etal. (1990), that the most common places that are vulnerable to injury are the knee, leg and ankle. (146: 15) (285: 14).

This result also aggress with what Ekstrand\&Gillquist referred to that foot joint torsion, bruises and knee joint injuries are due to the insufficient rehabilitation after recovery or to mistakes in training method. (175: 12).

By displaying and discussing the previous table, the second question has been answered which is: What are the differences between places of the most common injuries in different champions in athletics players? 
Third: Results Display of Third Question

Table (4)

The reason behind sport injuries of athletics players

\begin{tabular}{|c|c|c|c|}
\hline No. & Reasons Behind Injury & C & $\%$ \\
\hline 1 & Bad planning of annual training program. & 140 & 63.64 \\
\hline 2 & Disintegrated physical fitness elements training. & 176 & 80.00 \\
\hline 3 & Trainers interest in some muscles and neglecting the others. & 120 & 45.55 \\
\hline 4 & Weak training ability of the coach & 108 & 49.09 \\
\hline 5 & Extra weight in training that excesses athlete's level & 138 & 62.73 \\
\hline 6 & Neglecting general physical fitness & 132 & 60.00 \\
\hline 7 & Lack of proficiency of sport skills. & 112 & 50.91 \\
\hline 8 & Lack of general periodical medical test & 136 & 61.82 \\
\hline 9 & Unsuitable sport clothes and tools & 176 & 80.00 \\
\hline 10 & Neglecting integrated nutrition & 124 & 56.36 \\
\hline 11 & Neglecting warming & 188 & 85.45 \\
\hline 12 & Unsuitable heat degree & 52 & 23.63 \\
\hline 13 & Unsuitable playground floor & 120 & 54.55 \\
\hline 14 & Disobeying law and arbitrator decisions & 112 & 50.91 \\
\hline 15 & Deliberate clash with players & 116 & 52.73 \\
\hline 16 & During physical preparation period & 106 & 48.19 \\
\hline 17 & During champions period & 140 & 63.64 \\
\hline 18 & During training & 180 & 81.82 \\
\hline 19 & Not completing the rehabilitation treatment period & 122 & 55.45 \\
\hline 20 & Lack of experience of sport rehabilitation specialists & 114 & 51.82 \\
\hline 21 & Long study load & 96 & 43.64 \\
\hline 22 & The disharmony between practical and theoretical & 98 & 44.55 \\
\hline 23 & unqualified arbitrators & 118 & 53.64 \\
\hline 24 & The physiotherapy specialist. & 36.09 \\
\hline 25 & total & 3088 & 1403.66 \\
\hline
\end{tabular}

Table (4) shows that the highest rate of reason behind injury is in order: neglecting warming, injury during training, unsuitable sport tools and clothes, Disintegrated physical fitness elements training, Bad planning of annual training program, during champions period, extra load in training and unqualified arbitrators.

\section{Result Discussion of Third Question}

Table (4) shows that the highest rate of reasons behind injury is neglecting warming by the rate $(85.45 \%)$. Nerman Mohamed Ali and others (1998) see that performing exercises, warming and stretching exercises of different body muscles decrease the injury risk and improve athlete's conception. (23: 9)

Followed by injury during training rated (81.82\%), Peter Thomas (1996) refers that the different and diverse reasons of sport injuries in Athletics can be due to trauma or excessive training or may be intrinsic or extrinsic factors. (69: 3)

Followed by Disintegrated physical fitness elements training and unsuitable sport tools and clothes rated $(80.00 \%)$. MagdyElhosseiny (1991) sees that unsuitable sport tools and clothes may cause many problems such as climate unsuitable clothes (15:6).

Followed by Bad planning of annual training program and during champions period rated $(63.64 \%)$ followed by extra load in training rated $(62.73 \%)$.

This agrees with what Rerstrom (2003) referred to that the increase of injuries during training rather during competitions is attached to recklessness, haste and love of practicing without paying attention to good warming or for psychological motives of training for longer time or not being committed to the training plans or that these plans do not suit players' capabilities as the big weekly increase of training doses does not suit body muscles' ability. Besides, the number of training times is much bigger than competitions practice times. (168: 17).

By displaying and discussing the previous table, the (third) question has been answered which is: 
What are the reasons behind athletics' sport injuries?

\section{Conclusions}

1. The highest rate of injury kinds was in order: rupture, bruising, cringe, torsion and the lowest rate was dislocation.

2. The highest rate of injury places was in order: the leg, hand, foot, knee, and shoulder, the lowest injury rate was the face as it did not record any injury in the face.

3. The most common injuries of running players are cringe, thigh, leg, knee and foot injuries. As for jump players are bruising, break, torsion, dislocation and elbow injuries. For throwing players are rupture, shoulder, hand, chest, and back.

4. The highest rate of injury occurrence is due to (in order): not paying attention to warming, injury during training, disintegrated physical fitness elements training, bad planning of training, during competitions period, extra load in training and unqualified arbitrators.

\section{Recommendations}

1. To make a study for players of running, jump, and throwing in order to recognize the sport injuries of each competition and their reasons.

2. To pay attention to preventive methods in order to avoid rupture, bruising and torsion injuries proved by this study.

3. To pay attention to preventive methods in order to avoid sport injuries in leg, hand, foot, knee and shoulder proved by this study.

4. To make a comparison study between upper and lower limbs of athletics players.

5. To make a study to define safety factors in order to decrease sport injuries of athletics players.

6. To circulate this study on trainers of athletics teams and physical education universities.

\section{References}

1. BashkYeron F. (1981): sources and treatment of athletics injuries, physical and sport culture, Moscow.

2. Botrnag A. (1974): physical therapy to rehabilitate athletics after limbs injuries, athletic medicine, Moscow.

3. Peter Thomas (1996) "the entry to training theories" the Athletics International Union for Amateurs", translated by the regional development center, Cairo.

4. Hssan, Adel Ali (1993): Analytic study on common injuries among students specialized in physical education, Bahrain University, sport sciences, Faculty of Education, Menya University, 5th volume, 1st issue, page 111.

5. Abdo Ali Nassif, KerhaRedmeser (1972), biomechanics, Menya Print house, Baghdad.

6. MagdyElhosseinyElewa (1991): sport injuries between prevention and treatment, Dar Alarkam, 1st edition, Cairo.

7. Mohammed Fathy Abdel Rahman (1982): introduction to sport injuries, Helwan University.

8. Mohammed FoadHabib (1996): "common injuries among beginners in gymnastics sport", scientific magazine for physical and sport education, 25th issue, April.

9. Nerman Mohammed Ali and others (1998): muscle stretching, Ketab publishing center.

10. NazmiDarwish and others (1985): sport injuries for track and field competitors, international conference for sport for all in developing countries "4th volume, Helwan University, Faculty of Physical Education, Cairo.

11. Darden , E . (1981): “The Athlete's guide injuries, -Sports Medicine Contemporary book, Canada Inc.

12. Ekstrand , j.lGillguist, J ( 1983 ) " Soccer injuries and sports exercise, their mechanisms . A prospective study. 15 . 267- 70 
13. John H, and Milliams, j.g (1961) sport injuries and their treatment Stanley paul London ,53

14. Mechelen , w . (1992) "Aetilongy and prevention of Running injuires "Thesis, Vrije Universities Amsterdam.

15. Oijendik,W.T.M\&Agt, l.v. (1990) "prevetntie van hard loopblessurtes (the prevention of Running injuries)" Gen . Sport 23(4) .146-151.
16. Balogun, Joseph .B.,( 1992): The effect of wobble board exercises training Program on Adesinas , C., and Static muscle Physiotherapy Canada. Feb. Marzouk ,D.

17. Renstrom, P. (2003) . "Clinical Practice of Sports InjuryPrevention and Care " . Olympic literature Kiev .

18. Vulpen,V: (1989) Sports Injuries and Their Prevention . Scientific Report, Council of Europe Coordinated Research Project (NISG2). 